\title{
Biosensors: frontiers in rapid detection of COVID-19
}

\author{
Rachel Samson ${ }^{1,2} \cdot$ Govinda R. Navale $^{1,2} \cdot$ Mahesh S. Dharne ${ }^{1,2} \mathbb{0}$ \\ Received: 8 June 2020 / Accepted: 27 July 2020 / Published online: 11 August 2020 \\ (c) King Abdulaziz City for Science and Technology 2020
}

\begin{abstract}
The rapid community-spread of novel human coronavirus 2019 (nCOVID19 or SARS-Cov2) and morbidity statistics has put forth an unprecedented urge for rapid diagnostics for quick and sensitive detection followed by contact tracing and containment strategies, especially when no vaccine or therapeutics are known. Currently, quantitative real-time polymerase chain reaction (qRT-PCR) is being used widely to detect COVID-19 from various types of biological specimens, which is time-consuming, labor-intensive and may not be rapidly deployable in remote or resource-limited settings. This might lead to hindrance in acquiring realistic data of infectivity and community spread of SARS-CoV-2 in the population. This review summarizes the existing status of current diagnostic methods, their possible limitations, and the advantages of biosensorbased diagnostics over the conventional ones for the detection of SARS-Cov-2. Novel biosensors used to detect RNA-viruses include CRISPR-Cas9 based paper strip, nucleic-acid based, aptamer-based, antigen-Au/Ag nanoparticles-based electrochemical biosensor, optical biosensor, and Surface Plasmon Resonance. These could be effective tools for rapid, authentic, portable, and more promising diagnosis in the current pandemic that has affected the world economies and humanity. Present challenges and future perspectives of developing robust biosensors devices for rapid, scalable, and sensitive detection and management of COVID-19 are presented in light of the test-test-test theme of the World Health Organization (WHO).
\end{abstract}

Keywords Biosensors $\cdot$ SARS-CoV-2 $\cdot$ COVID-19 $\cdot$ Rapid detection

\section{Introduction}

In December 2019, severe respiratory distress, with pneumonia-like symptoms was reported in Wuhan, China. The metagenomic RNA sequencing from the bronchoalveolar lavage fluid of the infected patients identified a new RNA virus (Zhou et al. 2020b). Later, the phylogenetic and genomic analyses revealed that the virus shares a close genetic resemblance to the SARS (Severe Acute Respiratory Syndrome) like coronavirus (Lu et al. 2020). Subsequently, the International Committee on Taxonomy of Viruses (ICTV) renamed the novel coronavirus (2019-nCOVID/

Rachel Samson and Govinda R. Navale contributed equally to this work.

Mahesh S. Dharne

ms.dharne@ncl.res.in

1 Academy of Scientific and Innovative Research (AcSIR), Ghaziabad, India

2 CSIR-National Chemical, Laboratory, National Collection of Industrial Microorganisms (NCIM), Biochemical Sciences Division, Pune, India
COVID-19) as Severe Acute Respiratory Syndrome Coronavirus 2 (SARS-CoV-2) (Lu et al. 2020). Since 12th March 2020, the pandemic of SARS-CoV-2 has been declared as Public Health Emergency of International Concern (PHEIC) by the WHO. To date, over fifteen million cases have been recorded across the globe. Besides the health crisis, the SARS-CoV-2 pandemic has also brought a socioeconomic crunch across the globe (Nicola et al. 2020). Until now, there are no specific treatment approaches or vaccines to confine the outbreak, like these under clinical trial stages (Hamid et al. 2020). Therefore, there is a necessity for immense diagnostic measures to curb the unprecedented virus transmission and to aid in the rapid diagnosis of COVID-19 and understand its epidemiology for therapeutic advancement.

SARS-CoV-2 has an incubation period of 2-7 days, before the onset of the infection. This stage is mostly asymptomatic and contagious as the virus can spread from one infected person to the other healthy one (Chan et al. 2020). The existing number of infected cases and the actual case fatality ratio (CFR) of the COVID-19 infected patients is still unclear due to a lack of uncertainties in quantifying or detecting the infection (Bohk-Ewald et al. 2020). Therefore, 
the extent of this pandemic is still notional. Testing people or a mass population for any viral infection involves biosensing of presence or absence of analytes such as viral nucleic acids (DNA and RNA), viral proteins, intact viral particles, and antibodies generated by the patient immune response against the virus (Guliy et al. 2019). The list of all viral diagnostic methods is summarized in Table 1.

Although a significant number of methods are available for detecting virus particles, there are several difficulties, that restrict the practical use of these methods. These limitations include:

1. Lower accuracy and sensitivity

2. The need for sample preparation and purification

3. Time-consuming

4. Higher instrument, accessories, and maintenance cost

5. Large-scale availability

6. The complex operation of the instruments

7. A requirement of highly qualified technical personnel

8. Not suitable for rapid, on-site analysis

Therefore, there is a need for newer, efficient methods for the rapid detection of viral analytes, which takes into consideration the versatility of viruses and their replication niches. Implementation of these methods must ensure higher accuracy, ease of operation and portability, and large-scale availability to test the mass population. The purpose of this review is to comprehend our understanding of different types of biosensors used in the diagnosis of viral respiratory infections, the recent advancement in trends of biosensor research for detection of SARS-CoV-2, and prospects of biosensors in rapid diagnosis of the mass population to contain the spread of this virus.

\section{Biosensors in the detection of human respiratory viruses}

Sensors consist of chemical or biological receptors and transducers. The receptor interacts specifically with a target analyte and the transducer converts the recognition process into a quantitative signal (Ozer et al. 2020). Biosensors are analytical devices in which biological recognition molecules such as enzymes, antibodies, or nucleic acids are coupled with a transducer and a detector that detects the interacted analyte and gives a digital output. Biosensors can

Table 1 Summary of viral diagnostic methods

\begin{tabular}{|c|c|}
\hline Diagnostic tests & References \\
\hline $\begin{array}{l}\text { Nucleic acid detection and amplification } \\
\text { PCR, RT-PCR, qPCR } \\
\text { Isothermal amplification technologies: (NASBA; } \\
\text { LAMP; HDA; RCA; NEAR; SDA; TMA) }\end{array}$ & $\begin{array}{l}\text { Fouchier et al. (2000), Storch (2000), Poon et al. (2005), Zhou et al. (2012), Sasaya (2015) } \\
\text { and Souf (2016) }\end{array}$ \\
\hline $\begin{array}{l}\text { Immunoassays } \\
\text { Fluorescent antibody (FA) Staining } \\
\text { Hemagglutination inhibition } \\
\text { Immuno-peroxidase Staining } \\
\text { EIA/ELISA (FPIA, MEIA, CLIA) }\end{array}$ & Gupta et al. (2015), Mixson-Hayden et al. (2015) and Cebeci Güler and Tosun (2017) \\
\hline $\begin{array}{l}\text { DNA sequencing } \\
\text { Sanger sequencers } \\
\text { Next-generation sequencers } \\
\text { DNA microarrays }\end{array}$ & $\begin{array}{l}\text { Chiu et al. (2008), Léveque et al. (2014), Fischer et al. (2015), Thorburn et al. (2015), } \\
\text { Wylie et al. (2018), Jerome et al. (2019), Huang et al. (2019) and Lewandowski et al. } \\
\text { (2020) }\end{array}$ \\
\hline $\begin{array}{l}\text { Mass spectrometric methods } \\
\text { MALDI-TOF }\end{array}$ & Léveque et al. 2014) and He et al. (2014) \\
\hline $\begin{array}{l}\text { Direct visualization of viruses } \\
\text { Electron microscopy }\end{array}$ & $\begin{array}{l}\text { Curry et al. (2006), Schramlová et al. (2010), Gabaldón and Carreté (2016) and Roingeard } \\
\text { et al. (2019) }\end{array}$ \\
\hline $\begin{array}{l}\text { Microelectronics and microfluidics based techniques } \\
\text { Lab-on-a-chip (LOC) technologies } \\
\text { Point of care (POC) testing } \\
\text { Surface Plasmon Resonance (SPR) technique }\end{array}$ & $\begin{array}{l}\text { Foudeh et al. (2012, Szabó et al. (2015), Dak et al. (2016), Koo et al. (2017), Soler et al. } \\
\text { (2019) and Zhu et al. (2020a) }\end{array}$ \\
\hline
\end{tabular}

$P C R$ polymerase chain reaction, $q P C R$ quantitative polymerase chain reaction, $R T-P C R$ real-time polymerase chain reaction, $N A S B A$ nucleic acid sequence-based amplification, $L A M P$ loop-mediated isothermal amplification, $H D A$ helicase dependent amplification, $R C A$ rolling circle amplification, NEAR nicking enzyme amplification reaction, SDA Strand displacement amplification, TMA transcription-mediated amplification, EIA/ELISA enzyme immunoassay/enzyme-linked immunosorbent assay, ESI electrospray ionization, FPIA fluorescence polarization immunoassay, MEIA Micro-particle enzyme immunoassay, MALDI-TOF Matrix-assisted laser desorption ionization time-of-flight 
be applied for medical diagnosis, environmental monitoring, food, water, and agricultural product processing are known (Rodovalho et al. 2015). Viral biosensors offer exciting alternatives to traditional diagnostic assays and can provide inexpensive, sensitive, rapid, miniaturized, and portable platforms when compared to conventional laboratory-based methods (Souf 2016).

In the past few decades, the innovation of biosensor research has witnessed an exceptional and exponential surge in the development and performance, due to advancements in transduction systems, nanotechnology and genetic engineering offer various strategies to improve the detection performance of biosensors (Cheng and Toh 2013). Based on technology incurred, there are four types of biosensors viz, Optical biosensors, Electrochemical biosensors, Piezoelectric biosensors, and Thermal biosensors (Saylan et al. 2019). A summary of different biosensor platforms for the detection of respiratory viral infections is listed in Table 2.

\section{Recent trends in biosensors for detection of SARS-CoV-2}

The COVID-19 pandemic is becoming more severe due to its continued global spread and the unavailability of appropriate therapy and diagnostics systems. International health agencies are making serious efforts to manage the COVID-19 epidemic by exploring every aspect of therapy development with special attention to investigating smart diagnostics tools needed for rapid and selective detection of the COVID-19 protein. The quest for rapid testing of mass populations for COVID-19 was documented by innovative methods in biosensor development (Nguyen et al. 2020). All possible targets of SARS-CoV-2 are depicted in Fig. 1 for testing viral genomic RNA, membrane proteins, and spike glycoproteins,

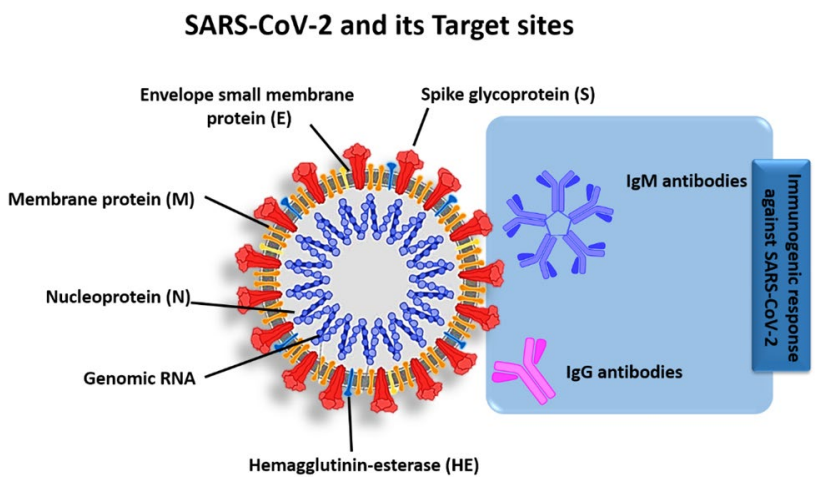

Fig. 1 Schematic structure of SARS-Cov-2 and its possible targets for diagnosing

which insist on immediate immune response upon binding to the host ACE-2 receptors (Liu et al. 2020). The humoral response is mediated by $\operatorname{IgM}$ and IgG antibodies, that are used to detect the COVID-19 disease and also used for its possible therapy known as plasma therapy (Chen et al. 2020; Zhang et al. 2020).

To overcome the issues mentioned above with conventional methods such as Lateral Flow Assay, ELISA, and colorimetric assay, etc. are time-consuming as well as low accuracy techniques. Many researchers worldwide are working on affordable, rapid, and highly sensitive methodologies or devices to detect 'the deadly viral pathogen'. To overcome limitations of qRT-PCR based assay, a recently highly specific RT-LAMP (Reverse Transcription Loop-Mediated Isothermal Amplification) assay based method is available for detection of SARS-CoV-2 (Zhu et al. 2020b; Park et al. 2020; Yu et al. 2020). In addition to the conventional RTLAMP method, Zhu et al., evaluated the one-step RT-LAMP mediated with Nanoparticles-Based Biosensor (NBS), RT-LAMP-NBS assay for rapid and accurate diagnosis of

Table 2 Types of biosensors for respiratory virus detection

\begin{tabular}{|c|c|c|c|c|}
\hline Types of portable Biosensor & Virus & Recognition element & Other viruses detected & References \\
\hline $\begin{array}{l}\text { Electrochemical Bio/Immu- } \\
\text { nosensor }\end{array}$ & Influenza A virus & M1 protein & $\begin{array}{l}\text { Parainfluenza; Rhinovirus; } \\
\text { Middle East respiratory } \\
\text { syndrome coronavirus } \\
\text { (MERS); Severe acute } \\
\text { respiratory syndrome } \\
\text { (SARS-CoV) }\end{array}$ & $\begin{array}{l}\text { Schmidt and Hawkins (2016), } \\
\text { Dziabowska et al. (2018) } \\
\text { and Saylan et al. (2019) }\end{array}$ \\
\hline Optical Bio/Immunosensor & MERS & $\begin{array}{l}\text { Recombinant Spike protein } \\
\text { S1 (Human betacoronavirus } \\
\text { 2c EMC/2012) }\end{array}$ & $\begin{array}{l}\text { SARS-CoV; } \mathrm{H}_{5} \mathrm{~N}_{1} \text { influenza } \\
\text { virus; Human Adenovirus; } \\
\text { Respiratory Syncytial Virus } \\
\text { (RSV); }\end{array}$ & $\begin{array}{l}\text { Layqah and Eissa (2019), } \\
\text { Ravina et al. (2020) and } \\
\text { Santiago 2020) }\end{array}$ \\
\hline Piezoelectric immunosensor & SARS-CoV & Spike protein $\mathrm{S} 1$ & $\begin{array}{l}\text { Influenza Virus; Adenovirus; } \\
\text { RSV; MERS }\end{array}$ & $\begin{array}{l}\text { Kizek et al. (2015), Yuan and } \\
\text { Han (2016) and Lee et al. } \\
\text { (2018) }\end{array}$ \\
\hline Thermal Biosensor & SARS-CoV & $\begin{array}{l}\text { RNA-dependent RNA poly- } \\
\text { merase }(R d R p) \text { gene }\end{array}$ & MERS; SARS-CoV-2 & $\begin{array}{l}\text { Saylan et al. (2019) and Woo } \\
\text { et al. (2020) }\end{array}$ \\
\hline
\end{tabular}


SARS-CoV-2. In this assay, LAMP primer sets, F1ab (opening reading frame $1 \mathrm{a} / \mathrm{b}$ ), and $n p$ (nucleoprotein) genes of SARS-CoV-2 were simultaneously amplified and detected in a one-step and single-tube reaction, and NBS could easily interpret these detection results. The sensitivity of SARSCoV-2 RT-LAMP-NBS was 12 copies (each of the detection targets) per reaction. This made it less error-prone in amplifying the non-SARS-CoV-2 templates, thus giving a higher specificity and low false positives results. Additionally, this report revealed $100 \%$ sensitivity for the detection of COVID19 in clinical samples (oropharynx swab samples) and it took about one hour for detection (Zhu et al. 2020b). Further, the use of modern gene-editing CRISPR-Cas (Clustered Regularly Interspaced Short Palindromic Repeats) system for the detection of the virus was studied (Zuo et al. 2017). This technique can also detect bacteria, microRNAs, and cancer mutations, in a simple and easily scalable manner, merely by changing target-specific crRNA/sgRNA. Recently, nanoparticles (NPs) gained enormous interest due to their biological activity and sensing properties (Holzinger et al.
2014; Navale et al. 2015b, c). The gene-editing technique was modified as a biological sensor using CRISPR-Chip coupled with a graphene-based Field Effect Transistor (FET) that can detect up to $1.7 \mathrm{fM}$ quantity of nucleic acid without the need for amplification within a short span of $15 \mathrm{~min}$ (Hajian et al. 2019). Recently, it was also established for the detection of COVID-19 infection in less than $40 \mathrm{~min}$. The CRISPR-Cas12-based lateral flow assay technique is easy to implement and an accurate and good replacement for real-time RT-PCR based diagnostics (Schematic Fig. 2a) (Broughton et al. 2020). The FET-based biosensing devices utilize the coating of the graphene sheets of the FET with a monoclonal antibody against the SARS-CoV-2 spike protein (Fig. 2b). They determined its sensitivity using antigen protein, cultured virus, and nasopharyngeal swab specimen from COVID-19 patients. This FET biosensor device could detect $1 \mathrm{fg} / \mathrm{mL}$ concentration (conc.) of SARS-CoV-2 spike protein in phosphate-buffered saline (PBS) and $100 \mathrm{fg} / \mathrm{mL}$ conc. in the clinical transport medium (Seo et al. 2020). Numerous nanoparticle-based electrochemical biosensor
(A)

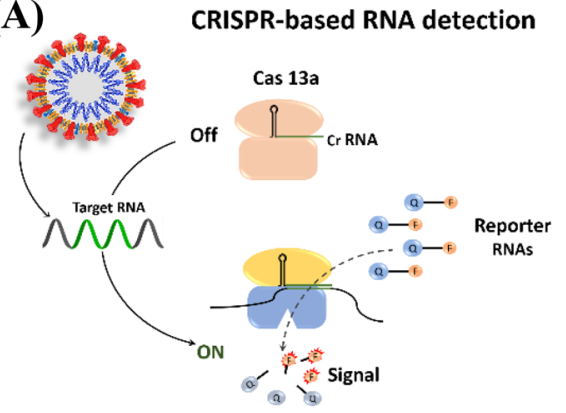

(C)

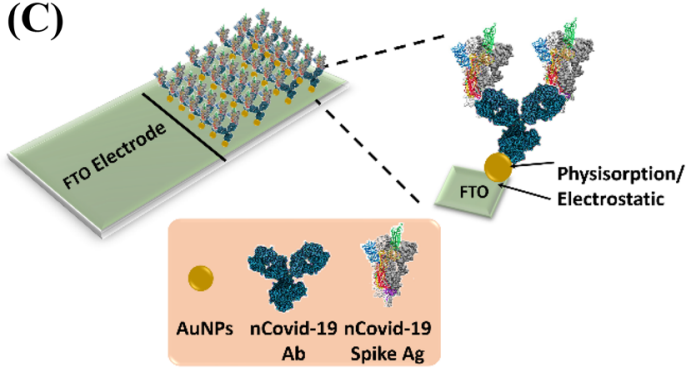

Au-NP based FTO electrode biosensor

(B)

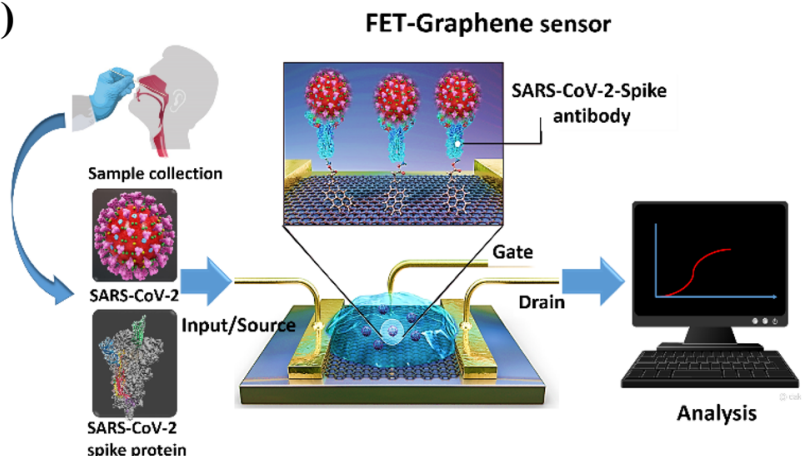

(D)

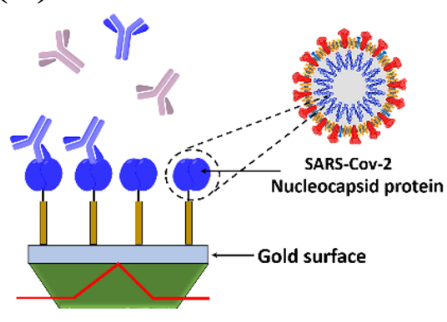

(E)

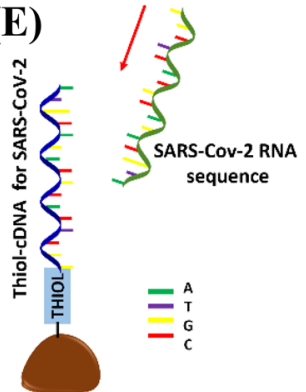

SPR based Biosensor
AuNI functionalization Biosensor
Fig. 2 Biosensors for SARS-CoV-2 virus detection. a CRISPR based nucleic acid (RNA) detection. RNA transcripts containing the target sequence (green) are recognized by RNA guided Cas endonuclease and CRISPR-RNA (Cr-RNA) carrying the complementary sequence. The formation of the Cas-crRNA-RNA-transcript tertiary complex switches on the 'collateral cleavage' activity, thereby dramatically applying the fluorescent signal in the presence of the target RNA. $Q$ quencher, $F$ fluorophore (Zuo et al. 2017; Broughton et al. 2020). b Schematic diagram of COVID-19 FET based biosensor operation. SARS-CoV-2 spike antibody is conjugated onto the graphene sheet via 1-pyrenebutyric acid $N$-hydroxy-succinimide ester, which is an interfacing molecule, as a probe linker (Seo et al. 2020). c The FTO electrode consist sensing area made up of AuNPs conjugated with nCOVID-19 Ab either by physisorption or electrostatic bonding (Mahari et al. 2020). d Surface Plasmon Resonance (SPR) based biosensor for COVID-19 detection. Activation of the AffiCoat surface, the nucleo-capsid protein of SARS-CoV-2 are bound to the SPR chip, and remaining activated sites were passivated with ethanolamine. $\mathbf{e}$ Schematic diagram of the 2D gold Nanoislands (AuNIs) functionalized with complementary thiol-cDNA ligands 
devices are also known for virus detection (Caygill et al. 2010). Recently Mahari et al., developed an in-house built biosensor device (eCovSens) which were fabricated with Fluorine Doped Tin Oxide (FTO) electrode together with gold nanoparticles (AuNPs) and nCOVID-19 antibody. They are very specific to detect the nCOVID-19 spike antigen. At optimal conditions, these FTO-Immunosensor could detect the nCOVID-19 antigen, ranging from $1 \mathrm{fM}$ to $1 \mu \mathrm{M}$ concentrations. This eCovSens device can detect nCOVID-19 antigen at $10 \mathrm{fM}$ concentration in a standard buffer. This device displays the results rapidly, within 10-30 s (Fig. 2c) (Mahari et al. 2020). Surface Plasmon Resonance (SPR) and Localized Surface Plasmon Resonance (LSPR) based viral biosensors were referred earlier (Park et al. 2009; Lee et al. 2018). These thermoplasmonic techniques are highly applicable in nucleic-acid detection and also in viral disease diagnosis. Recently, this SPR based sensor was reported for detecting nucleocapsid antibodies, which were specific against the SARS-CoV-2 in undiluted human serum instead of oropharynx swab. This SPR sensor coated with a peptide monolayer and functionalized with SARS-CoV-2 nucleocapsid's recombinant protein detected anti-SARS-CoV-2 antibodies in the $\mathrm{nM}$ range. Thus, this bioassay is rapid, label-free which can diagnose samples within 15 min of sample/sensor contact (Fig. 2d) (Djaileb et al. 2020). For the detection of current pandemic (SARS-CoV-2), dual-functional, plasmonic biosensor Plasmonic Photothermal (PPT) and LSPR were also explored. The 2D gold nanoislands (AuNIs) functionalied with complementary DNA (cDNA) receptors and combining PPT effect and LSPR sensing technique, provides an alternative and promising solution for the detection of clinical COVID-19 by nucleic acid hybridization (Fig. 2e). This dual-functional LSPR biosensor exhibits a high sensitivity towards the selected SARS-CoV-2 sequences, with a detection limit up to $0.22 \mathrm{pM}$ conc. which allows precise detection of the specific target in a multigene mixture (Qiu et al. 2020).

\section{Future perspectives of biosensors for the detection of SARS-CoV-2}

Currently, to overcome this 2020 pandemic of SARS$\mathrm{CoV}-2$, there is much interest in developing rapid, reliable, and sensitive novel biosensors for COVID-19 diagnostics which would be a single step identification or sensing method that eliminate separation (extraction of nucleic acid), incubation or use of any signal-reporting agents. Biosensors for COVID-19 are mostly designed on the surface nucleoproteins, which binds to the host angiotensin-converting enzyme 2 (ACE-2) receptor and the internal genetic material; is very specific (Liu et al. 2020). Detection of biomarkers from human hosts different from antibodies or immunoglobulins could be the approach for developing new biosensors for COVID-19 infection. Recently, several host biomarkers such as hematological (lymphocyte count, neutrophil count, neutrophil-lymphocyte ratio (NLR)), inflammatory (C-reactive protein (CRP), erythrocyte sedimentation rate (ESR), procalcitonin (PCT)), immunological (interleukin (IL)-6 and biochemical (D-dimer, troponin, creatine kinase (CK), aspartate aminotransferase (AST)), especially those related to coagulation cascades in disseminated intravascular coagulation (DIC) and acute respiratory distress syndrome (ARDS) are identified. Other novel biomarkers can be identified through the accurate analysis of multiple case studies, in particular, homocysteine and angiotensin II could play a significant role (Ponti et al. 2020). In recent years, nanomaterials such as gold and carbon have gained vast interest in sensor technology and have produced promising devices for sensing the virus and its biomolecules. These nanomaterials fused with analyte such as complementary single-stranded nucleic acid aptamer could be a new strategy for detecting SARS-CoV-2 in clinical samples. Aptamers are single-stranded RNA or DNA oligonucleotides which depend on hydrogen bonding, electrostatic, and hydrophobic interactions, and they represent an alternative to antibodies as recognition agents. Aptamer based bio-nanogate bifunctional biosensor specifically respond to the viral surface spike protein $\mathrm{S} 1$ as a target molecules, and control enzymatic reaction for electrochemical measurements (Fig. 3a) (Wang et al. 2015; Acquah et al. 2016). The current scenario is heading in developing sensitive, portable, and space-friendly biosensor devices. Electrochemical based biosensors are based on electrode material and form factor, and widely being used for virus detection based on, antibodies, aptamers, and imprinted polymers (Cesewski and Johnson 2020). Ebola virus was diagnosed using the electrochemical-based DNA-sensing device, by an enzyme-amplified detection, which improved the sensitivity and selectivity of the sensor. As shown in Fig. 3b, the thiolated DNA capture probe sequence has been immobilized on the screen-printed electrode surface and hybridized with biotinylated target strand DNA. This strategy could be useful for detecting the SARS-CoV-2 virus by changing the immobilized thiolated nucleic acid sequence. This technique could detect $4.7 \mathrm{nM}$ conc. of complementary nucleic acids. This biosensor is selective and yields reproducible results (Ilkhani and Farhad 2018). Another electrochemical, paper-based biosensor was deployed for the detection of the chikungunya virus. These electrochemical paper-based biosensors used the ultra-high charge-transfer efficiency AuNPs associated with magnetic NPs (Fe2O4). This paper-based biosensor is simple, sensitive, biodegradable, and economic for mass production. The detection of COVID-19

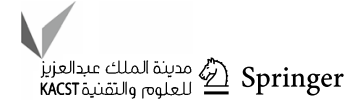


Fig. 3 Schematic representation of possible biosensors for detecting SARS-CoV-2. a Aptamer based Bio-nanogate biosensor for virus spike protein-specific detection. b Electrochemical biosensor for detecting nucleic acids in the sample. c DhITACT-TR Chip for robust detection of target pathogen in a single-step injection of RNA extract
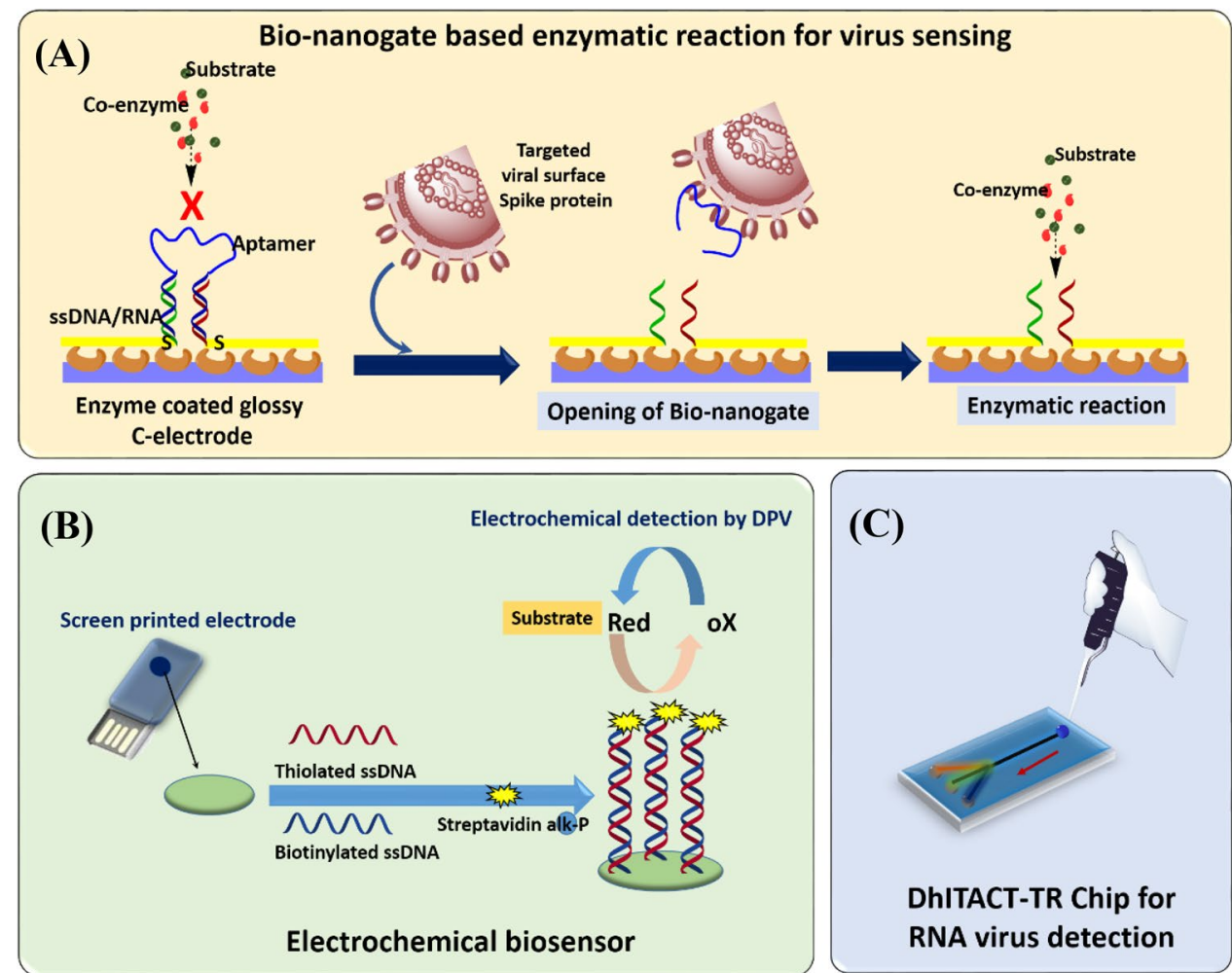

needs to be modified as per the specificity of the virus (Singhal et al. 2018). Meso/macroporous cobalt (II) oxide nanoflakes based electrochemical biosensor could detect $0.28 \mathrm{ng} / \mu \mathrm{L}$ conc. of specific RNA/DNA samples (Mohammadi et al. 2017).

For developing new biosensors, non-labeling techniques such as SPR, Surface-Enhanced Raman Scattering (SERS) and Quartz-Crystal Microbalance (QCM) technologies have shown promising development in biosensor research for viral samples. Such biosensors are in use for the detection of RNA viruses, such as influenza A/B, SARS-Corona, Ebola, MERS, Zika, and Dengue (Ilkhani and Farhad 2018; Soler et al. 2019). Ngo et al., developed a plasmonic SERSactive nanowave chip for single-step detection of nucleic acid. These techniques could also be used to develop a new biosensor for COVID-19 detection, as they allow detection of host genetic biomarkers for respiratory viral infection and a specific nucleic acid sequence (Ngo et al. 2016). The AgNPs hybridization in a quartz crystal microbalance DNAQCM sensing system might be useful for the detection of RNA viruses over the conventional PCR based approaches (Chen et al. 2009). Detection of nucleocapsid protein is one of the keys to detecting viruses. Localized Surface Plasmon Coupled Fluorescence (LSPCF) fiber-optic biosensor was studied a decade ago for diagnosing different SARS viruses. This plasmon-based biosensor has combined sandwich immunoassay with the LSP technique and detects $0.1 \mathrm{pg} /$ $\mathrm{mL}$ to $1 \mathrm{ng} / \mathrm{mL} \mathrm{SARS}-\mathrm{CoV} \mathrm{N}$ protein in serum samples.
This biosensor could also detect the SARS-CoV-2 virus (Huang et al. 2009). Similarly, Park et al. (2009) revealed a self-assembled fusion protein-based SPR biosensor for rapid and acute diagnosis of the SARS virus.

Ionic liquids are the well-known solvents, that are synthesized by various combinations of cations and anions, and widely used in green chemistry and other biological applications (Navale et al. 2015a; Venkatraman et al. 2019). Most of the biosensors or other viral detection methods are required quick and stable RNA extraction steps. Lately, hydrophobic magnetic ionic liquids are used for isolation of RNA (as well as DNA) and also aided in the preservation of RNA, and hence it could be used during the initial step of viral RNA extraction. Recently Zhou et al., developed a DNA nano switch; an automated, low-cost, and rapid detection method for RNA viruses specifically using the Zika virus as a model system. This method detects viruses in a nonenzymatic manner and could detect at nanomoles of an RNA virus. This assay requires only a sample preparation step using either RNA extraction or isothermal pre-amplification. Recently, similar authors also evaluated such automated DNA nano-switches to detect SARS-CoV-2 RNA in human saliva (Zhou et al. 2020a). A novel DNA hydrogel formation by isothermal amplification of complementary target (DhITACT-TR) system has been successfully used for detection of the MERS virus, which is highly sensitive and could be diagnosed by the naked eye, as well as fluorescent detection within a short time (Fig. 3c). This biosensor is 


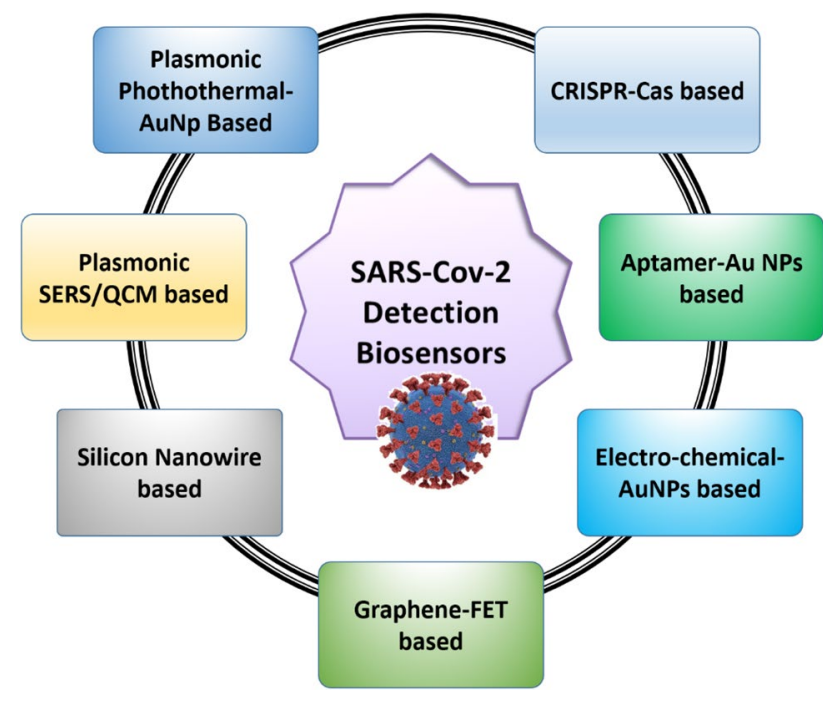

Fig. 4 The schematic diagram for biosensors for detection SARSCov-2 virus includes CRISPR-Cas based RNA detection; aptamerAu NPs based viral spike protein detection; electrochemical-AuNPs based viral RNA detection; graphene-field effect transistor biosensor for virus detection, silicon nanowire-based viral spike protein detection; non-labeling plasmonic techniques such as Surface Plasmon Resonance (SPR), surface-enhanced Raman scattering (SERS) and quartz-crystal microbalance (QCM) based biosensor for COVID-19

much better than conventional PCR based methods, which requires only RNA extracts and faster (Jung et al. 2016). Layqah et al., evaluated an immunosensor for the diagnosis of MERS-CoV, based on carbon electrodes (DEP) modified with AuNPs, wherein spike protein S1 was used as a biomarker. This assay was performed in just $20 \mathrm{~min}$ with a detection limit as low as 0.4 and $1.0 \mathrm{pg} / \mathrm{mL}$ for $\mathrm{HCoV}$ and MERS-CoV, respectively. This biosensor is a highly selective, single step, sensitive, and accurate (Layqah and Eissa 2019). Apart from AuNPs, Silicon nanowire (SiNW) based biosensor devices are also accurate and sensitive to detect viral infections, this could thus be used for detecting recent pandemic SARS-Cov-2 virus (Shen et al. 2012) (Fig. 4).

\section{Concluding remarks}

In conclusion, this review summarizes an overview of the traditional viral detection techniques and modern biosensorbased methods for the detection of the SARS-CoV-2 virus in the COVID-19 pandemic. Traditional techniques like PCR and sequencing are time-consuming and may have specific individual false positive outputs. However, these methods might not fulfill the new challenges (such as rapid mutations) and demands (for mass populations) for the faster and direct detection of viral pathogens. Sensors are mostly based on detecting virus surface proteins and internal genetic material. In near future, emerging new technologies such as rapid cum portable RNA extraction preps, CRISPR-Cas based paper strip, aptamer-based bio-naogate, nucleic acid hybridization, DhITACT-TR chip-based, graphene-FET, Au/ Ag nanoparticles based electrochemical biosensor, optical biosensor, and surface plasmon (SPR, SERS, and QCM) based innovative platforms could pave the efficient ways of rapid, highly sensitive and more promising biosensing cum diagnostic devices for COVID-19 and other unprecedented pandemics.

Acknowledgements The authors are thankful to Director, CSIRNational Chemical Laboratory, India for constant support and encouragement. Authors are indebted to Science Engineering and Research Board (SERB), New Delhi, India for providing funding under CRG Short-term special call on COVID-19 (CVD/2020/001002).

\section{Compliance with ethical standards}

Conflict of interest The authors have declared no conflict of interest.

\section{References}

Acquah C, Danquah MK, Agyei D et al (2016) Deploying aptameric sensing technology for rapid pandemic monitoring. Crit Rev Biotechnol 36:1010-1022. https://doi.org/10.3109/07388 551.2015.1083940

Bohk-Ewald C, Dudel C, Myrskyla M (2020) A demographic scaling model for estimating the total number of COVID-19 infections. medRxiv. https://doi.org/10.1101/2020.04.23.20077719

Broughton JP, Deng X, Yu G et al (2020) CRISPR-Cas12-based detection of SARS-CoV-2. Nat Biotechnol. https://doi.org/10.1038/ s41587-020-0513-4

Caygill RL, Blair GE, Millner PA (2010) A review on viral biosensors to detect human pathogens. Anal Chim Acta 681:8-15. https://doi. org/10.1016/j.aca.2010.09.038

Cebeci Güler N, Tosun AF (2017) The identification of Meyerozyma guilliermondii from blood cultures and surveillance samples in a university hospital in Northeast Turkey: a ten-year survey. J Mycol Med 27:506-513. https://doi.org/10.1016/j.mycmed.2017.07.007

Cesewski E, Johnson BN (2020) Electrochemical biosensors for pathogen detection. Biosens Bioelectron 159:112214

Chan JFW, Yuan S, Kok KH et al (2020) A familial cluster of pneumonia associated with the 2019 novel coronavirus indicating person-to-person transmission: a study of a family cluster. Lancet 395:514-523. https://doi.org/10.1016/S0140-6736(20)30154-9

Chen S-H, Chuang Y-C, Lu Y-C et al (2009) A method of layer-by-layer gold nanoparticle hybridization in a quartz crystal microbalance DNA sensing system used to detect dengue virus. Nanotechnology 20:215501. https://doi.org/10.1088/0957-4484/20/21/215501

Chen L, Xiong J, Bao L, Shi Y (2020) Convalescent plasma as a potential therapy for COVID-19. Lancet Infect Dis 20:398-400

Cheng MS, Toh CS (2013) Novel biosensing methodologies for ultrasensitive detection of viruses. Analyst 138:6219-6229

Chiu CY, Urisman A, Greenhow TL et al (2008) Utility of DNA microarrays for detection of viruses in acute respiratory tract infections in children. J Pediatrics. https://doi.org/10.1016/j.jpeds .2007 .12 .035

Curry A, Appleton H, Dowsett B (2006) Application of transmission electron microscopy to the clinical study of viral and bacterial infections: present and future. Micron 37:91-106

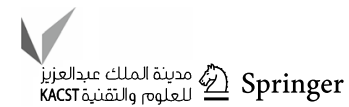


Dak P, Ebrahimi A, Swaminathan V et al (2016) Droplet-based biosensing for lab-on-a-chip, open microfluidics platforms. Biosensors $6: 14$

Djaileb A, Charron B, Jodaylami MH et al (2020) A rapid and quantitative serum test for SARS-CoV-2 antibodies with portable surface plasmon resonance sensing. Chemrxiv. https://doi.org/10.26434/ chemrxiv.12118914.v1

Dziabowska K, Czaczyk E, Nidzworski D (2018) Detection methods of human and animal influenza virus-current trends. Biosensors 8:94

Fischer N, Indenbirken D, Meyer T et al (2015) Evaluation of unbiased next-generation sequencing of RNA (RNA-seq) as a diagnostic method in influenza virus-positive respiratory samples. J Clin Microbiol 53:2238-2250. https://doi.org/10.1128/JCM.02495-14

Fouchier RAM, Bestebroer TM, Herfst S et al (2000) Detection of influenza a viruses from different species by PCR amplification of conserved sequences in the matrix gene. J Clin Microbiol 38:40964101. https://doi.org/10.1128/jcm.38.11.4096-4101.2000

Foudeh AM, Fatanat Didar T, Veres T, Tabrizian M (2012) Microfluidic designs and techniques using lab-on-a-chip devices for pathogen detection for point-of-care diagnostics. Lab Chip 12:3249-3266

Gabaldón T, Carreté L (2016) The birth of a deadly yeast: tracing the evolutionary emergence of virulence traits in Candida glabrata. FEMS Yeast Res 16:110

Guliy OI, Zaitsev BD, Larionova OS, Borodina IA (2019) Russian Text (C) The Author(s). Biophysics (Oxf) 64:1094-1102. https:// doi.org/10.1134/S0006350919060095

Gupta E, Pandey P, Kumar A et al (2015) Correlation between two chemiluminescence based assays for quantifi cation of hepatitis B surface antigen in patients with chronic hepatitis B infection. Indian J Med Microbiol 33:96-100. https://doi.org/10.4103/02550857.148400

Hajian R, Balderston S, Tran T et al (2019) Detection of unamplified target genes via CRISPR-Cas9 immobilized on a graphene field-effect transistor. Nat Biomed Eng 3:427-437. https://doi. org/10.1038/s41551-019-0371-x

Hamid S, Mir MY, Rohela GK (2020) Novel coronavirus disease (COVID-19): a pandemic (epidemiology, pathogenesis, and potential therapeutics). New Microbes New Infect 35:100679

He Q, Zhu Z, Jin L et al (2014) Detection of HIV-1 p24 antigen using streptavidin-biotin and gold nanoparticles based immunoassay by inductively coupled plasma mass spectrometry. J Anal At Spectrom 29:1477-1482. https://doi.org/10.1039/c4ja00026a

Holzinger M, Le Goff A, Cosnier S (2014) Nanomaterials for biosensing applications: a review. Front Chem 2:63. https://doi. org/10.3389/fchem.2014.00063

Huang JC, Chang Y-F, Chen K-H et al (2009) Detection of severe acute respiratory syndrome (SARS) coronavirus nucleocapsid protein in human serum using a localized surface plasmon coupled fluorescence fiber-optic biosensor. Biosens Bioelectron 25:320-325

Huang B, Jennsion A, Whiley D et al (2019) Illumina sequencing of clinical samples for virus detection in a public health laboratory. Sci Rep 9:1-8. https://doi.org/10.1038/s41598-019-41830-w

Ilkhani H, Farhad S (2018) A novel electrochemical DNA biosensor for Ebola virus detection. Anal Biochem 557:151-155. https://doi. org/10.1016/j.ab.2018.06.010

Jerome H, Taylor C, Sreenu VB et al (2019) Metagenomic next-generation sequencing aids the diagnosis of viral infections in febrile returning travelers. J Infect 79:383-388. https://doi.org/10.1016/j. jinf.2019.08.003

Jung IY, You JB, Choi BR et al (2016) A highly sensitive molecular detection platform for robust and facile diagnosis of Middle East Respiratory Syndrome (MERS) Corona Virus. Adv Healthc Mater 5:2168-2173. https://doi.org/10.1002/adhm.201600334
Kizek R, Krejcova L, Michalek P et al (2015) Nanoscale virus biosensors: state of the art. Nanobiosensors Dis Diagnosis 4:47. https:// doi.org/10.2147/ndd.s56771

Koo KM, Wee EJH, Wang Y, Trau M (2017) Enabling miniaturised personalised diagnostics: fFrom lab-on-a-chip to lab-in-a-drop. Lab Chip 17:3200-3220

Layqah LA, Eissa S (2019) An electrochemical immunosensor for the corona virus associated with the Middle East respiratory syndrome using an array of gold nanoparticle-modified carbon electrodes. Microchim Acta. https://doi.org/10.1007/s0060 4-019-3345-5

Lee T, Ahn JH, Park SY et al (2018) Recent advances in AIV biosensors composed of nanobio hybrid material. Micromachines 9:651

Léveque N, Legoff J, Mengelle C et al (2014) Virological diagnosis of central nervous system infections by use of pcr coupled with mass spectrometry analysis of cerebrospinal fluid samples. J Clin Microbiol 52:212-217. https://doi.org/10.1128/JCM.02270-13

Lewandowski K, Xu Y, Pullan ST et al (2020) Metagenomic nanopore sequencing of influenza virus direct from clinical respiratory samples. J Clin Microbiol. https://doi.org/10.1128/JCM.00963-19

Liu Z, Xiao X, Wei X et al (2020) Composition and divergence of coronavirus spike proteins and host ACE2 receptors predict potential intermediate hosts of SARS-CoV-2. J Med Virol 92:595-601. https://doi.org/10.1002/jmv.25726

Lu R, Zhao X, Li J et al (2020) Genomic characterisation and epidemiology of 2019 novel coronavirus: implications for virus origins and receptor binding. Lancet 395:565-574. https://doi. org/10.1016/S0140-6736(20)30251-8

Mahari S, Roberts A, Shahdeo D, Gandhi S (2020) eCovSens-ultrasensitive novel in-house built printed circuit board based electrochemical device for rapid detection of nCovid-19. bioRxiv. https ://doi.org/10.1101/2020.04.24.059204

Mixson-Hayden T, Dawson GJ, Teshale E et al (2015) Performance of ARCHITECT HCV core antigen test with specimens from US plasma donors and injecting drug users. J Clin Virol 66:15-18. https://doi.org/10.1016/j.jcv.2015.02.015

Mohammadi J, Moattari A, Sattarahmady N et al (2017) Electrochemical biosensing of influenza A subtype genome based on meso/macroporous cobalt (II) oxide nanoflakes-applied to human samples. Anal Chim Acta 979:51-57. https://doi.org/10.1016/j. aca.2017.05.010

Navale GR, Dharne MS, Shinde SS (2015a) Antibiofilm activity of tert-BuOH functionalized ionic liquids with methylsulfonate counteranions. RSC Adv 5:68136-68142. https://doi.org/10.1039/ c5ra12854d

Navale GR, Rout CS, Gohil KN et al (2015b) Oxidative and membrane stress-mediated antibacterial activity of WS 2 and rGO-WS 2 nanosheets. RSC Adv 5:74726-74733. https://doi.org/10.1039/ C5RA15652A

Navale GR, Thripuranthaka M, Late DJ, Shinde SS (2015c) Antimicrobial activity of $\mathrm{ZnO}$ nanoparticles against pathogenic bacteria and fungi. JSM Nanotechnol Nanomedicine 3:1033

Ngo HT, Wang HN, Fales AM, Vo-Dinh T (2016) Plasmonic SERS biosensing nanochips for DNA detection. Anal Bioanal Chem 408:1773-1781. https://doi.org/10.1007/s00216-015-9121-4

Nguyen T, Bang DD, Wolff A (2020) 2019 Novel coronavirus disease (COVID-19): paving the road for rapid detection and point-ofcare diagnostics. Micromachines 11:1-7. https://doi.org/10.3390/ MI11030306

Nicola M, Alsafi Z, Sohrabi C et al (2020) The socio-economic implications of the coronavirus and COVID-19 pandemic: a review. Int J Surg 78:185-193. https://doi.org/10.1016/j.ijsu.2020.04.018

Ozer T, Geiss BJ, Henry CS (2020) Review—chemical and biological sensors for viral detection. J Electrochem Soc 167:037523. https ://doi.org/10.1149/2.0232003jes 
Park TJ, Hyun MS, Lee HJ et al (2009) A self-assembled fusion protein-based surface plasmon resonance biosensor for rapid diagnosis of severe acute respiratory syndrome. Talanta 79:295-301

Park G-S, Ku K, Baek S-H et al (2020) Development of reverse transcription loop-mediated isothermal amplification assays targeting severe acute respiratory syndrome coronavirus 2. J Mol Diagnostics. https://doi.org/10.1016/j.jmoldx.2020.03.006

Ponti G, Maccaferri M, Ruini C et al (2020) Biomarkers associated with COVID-19 disease progression. Crit Rev Clin Lab Sci 5:111. https://doi.org/10.1080/10408363.2020.1770685

Poon LLM, Leung CSW, Chan KH et al (2005) Detection of human influenza A viruses by loop-mediated isothermal amplification. J Clin Microbiol 43:427-430. https://doi.org/10.1128/ JCM.43.1.427-430.2005

Qiu G, Gai Z, Tao Y et al (2020) Dual-functional plasmonic photothermal biosensors for highly accurate severe acute respiratory syndrome coronavirus 2 detection. ACS Nano. https://doi. org/10.1021/acsnano.0c02439

Ravina DA, Mohan H et al (2020) Detection methods for influenza A H1N1 virus with special reference to biosensors: a review. Biosci Rep. https://doi.org/10.1042/BSR20193852

Rodovalho V, Alves L, Castro A et al (2015) Biosensors applied to diagnosis of infectious diseases-an update. Austin J Biosens Bioelectron 1:1-12

Roingeard P, Raynal PI, Eymieux S, Blanchard E (2019) Virus detection by transmission electron microscopy: Still useful for diagnosis and a plus for biosafety. Rev Med Virol. https://doi. org/10.1002/rmv.2019

Santiago I (2020) Trends and innovations in biosensors for COVID-19 mass testing. Chem Bio Chem. https://doi.org/10.1002/cbic.20200 0250

Sasaya T (2015) Detection methods for rice viruses by a reversetranscription loop-mediated isothermal amplifi cation (Rt-lamp). Methods Mol Biol 1236:49-59. https://doi. org/10.1007/978-1-4939-1743-3_5

Saylan Y, Erdem Ö, Ünal S, Denizli A (2019) An alternative medical diagnosis method: biosensors for virus detection. Biosensors. https://doi.org/10.3390/bios9020065

Schmidt H, Hawkins AR (2016) Single-virus analysis through chipbased optical detection. Bioanalysis 8:867-870

Schramlová J, Arientová S, Hulínská D (2010) The role of electron microscopy in the rapid diagnosis of viral infections-review. Folia Microbiol (Praha) 55:88-101

Seo G, Lee G, Kim MJ et al (2020) Rapid detection of COVID-19 causative virus (SARS-CoV-2) in human nasopharyngeal swab specimens using field-effect transistor-based biosensor. ACS Nano. https://doi.org/10.1021/acsnano.0c02823

Shen F, Wang J, Xu Z et al (2012) Rapid flu diagnosis using silicon nanowire sensor. Nano Lett 12:3722-3730. https://doi. org/10.1021/nl301516z

Singhal C, Dubey A, Mathur A et al (2018) Paper based DNA biosensor for detection of chikungunya virus using gold shells coated magnetic nanocubes. Process Biochem. https://doi.org/10.1016/j. procbio.2018.08.020

Soler M, Huertas CS, Lechuga LM (2019) Label-free plasmonic biosensors for point-of-care diagnostics: a review. Expert Rev Mol Diagn 19:71-81
Souf S (2016) Recent advances in diagnostic testing for viral infections. Biosci Horizons Int J Student Res. https://doi.org/10.1093/BIOHO RIZONS/HZW010

Storch GA (2000) Diagnostic virology. Clin Infect Dis 31:739-751. https://doi.org/10.1086/314015

Szabó B, Borbíró A, Fürjes P (2015) Lab-on-a-chip systems in the point-of-care diagnostics. Orv Hetil 156:2096-2102. https://doi. org/10.1556/650.2015.30326

Thorburn F, Bennett S, Modha S et al (2015) The use of next generation sequencing in the diagnosis and typing of respiratory infections. J Clin Virol 69:96-100. https://doi.org/10.1016/j.jcv.2015.06.082

Venkatraman V, Evjen S, Lethesh KC et al (2019) Rapid, comprehensive screening of ionic liquids towards sustainable applications. Sustain Energy Fuels 3:2798-2808. https://doi.org/10.1039/ C9SE00472F

Wang R, Xu L, Li Y (2015) Bio-nanogate controlled enzymatic reaction for virus sensing. Biosens Bioelectron 67:400-407. https:// doi.org/10.1016/j.bios.2014.08.071

Woo CH, Jang S, Shin G et al (2020) Sensitive one-step isothermal detection of pathogen-derived RNAs. medRxiv. https://doi. org/10.1101/2020.03.05.20031971

Wylie KM, Wylie TN, Buller R et al (2018) Detection of viruses in clinical samples by use of metagenomic sequencing and targeted sequence capture. J Clin Microbiol. https://doi.org/10.1128/ JCM.01123-18

Yu L, Wu S, Hao X et al (2020) Rapid detection of COVID-19 coronavirus using a reverse transcriptional loop-mediated isothermal amplification (RT-LAMP) diagnostic platform. Clin Chem. https ://doi.org/10.1093/clinchem/hvaa102

Yuan YJ, Han K (2016) Development of a real-time QCM bond-rupture system for POCT applications. IEEE Sens J 16:8731-8735. https ://doi.org/10.1109/JSEN.2016.2563167

Zhang J, Xie B, Hashimoto K (2020) Current status of potential therapeutic candidates for the COVID-19 crisis. Brain Behav Immun 87:59-73

Zhou T, Du L, Fan Y, Zhou Y (2012) Reverse transcription loopmediated isothermal amplification of RNA for sensitive and rapid detection of southern rice black-streaked dwarf virus. J Virol Methods 180:91-95. https://doi.org/10.1016/j.jviro met.2011.12.014

Zhou L, Chandrasekaran AR, Punnoose JA et al (2020a) Programmable low-cost DNA-based platform for viral RNA detection. bioRxiv. https://doi.org/10.1101/2020.01.12.902452

Zhou P, Yang X-L, Wang X-G et al (2020b) Discovery of a novel coronavirus associated with the recent pneumonia outbreak in humans and its potential bat origin. Nature. https://doi. org/10.1101/2020.01.22.914952

Zhu H, Fohlerová Z, Pekárek J et al (2020a) Recent advances in labon-a-chip technologies for viral diagnosis. Biosens Bioelectron 153:112041

Zhu X, Wang X, Han L et al (2020b) Reverse transcription loopmediated isothermal amplification combined with nanoparticlesbased biosensor for diagnosis of COVID-19. medRxiv. https://doi. org/10.1101/2020.03.17.20037796

Zuo X, Fan C, Chen HY (2017) Biosensing: CRISPR-powered diagnostics. Nat Biomed Eng 1:1-2. https://doi.org/10.1038/s4155 $1-017-0091$ 